\title{
AKGÜNEY TOPLUMUNDA NADİR GÖRÜLEN BİR PATOLOJİ ÖRNEĞİ: STAFNE KIST
}

Ayşegül ŞARBAK*

Atıf/(): Şarbak, Ayşegül (2018). Akgüney Toplumunda Nadir Görülen Bir Patoloji Örneği: Stafne Kist, Hitit Üniversitesi Sosyal Bilimler Enstitüsü Dergisi, ANARSAN Sempozyumu Özel Sayısı, Ekim 2018, Cilt 11 Sayı 2, ss. 977-990

Özet: $\quad$ Stafne cavity, Stafne defekt, lingual kortikal mandibular defekt gibi isimlerle de bilinen Stafne Kist ilk defa Edward Stafne tarafindan 1942 yılinda tanımlanmiştır. Stafne Kist mandibulanin lingual tarafinda, anterior, posterior ya da ramus bölgesinde yer alır. Çoğunlukla unlateral olarak görülse de nadiren bilteral olarak da görülebilir. Stafne kist yuvarlak ya da oval şekillidir ve genişliği 1-3 cm arasında değişmektedir. Yaşayan toplumlarda Stafne kistin bulunma sıklı̆ı \%0,1-0,48 arasindadir. Arkeolojik toplumlarda daha nadir karşılaşılan Stafne Kist, Geç Roma-Bizans dönemine tarihlendirilen Akgüney toplumunda \%2,43 olarak belirlenmiştir. Araştırmalarda çoğunlukla orta erişkin erkek bireylerde daha sık gözlemlenen Stafne Kist, Akgüney toplumunda genç erişkin bir kadın bireyde tespit edilmiştir. Çalışmanın amacı Geç Roma-Bizans dönemine tarihlendirilen Akgüney toplumunda görülen stafne kist sıklığını belirlemektir.

Anahtar Kelimeler: Stafne Kist, Akgüney, Bizans

Makale Gelis Tarihi:21.09.2018 / Makale Kabul Tarihi: 15.10.2018

Bu makale Turnitin programinda kontrol edildi. This article was checked by Turnitin. Bu makale ANARSAN sempozyumunda sunulmuş aynı başlıklı bildirinin tam metnidir. *Dr.Öğr. Üyesi, Hitit Üniversitesi, Antropoloji Bölümü, aysegulsarbak@hitit.edu.tr 


\section{The Example of Rare Pathology In The Akgüney Population: Stafne Cyst}

Citation/O: Şarbak, Ayşegül (2018). The Example of Rare Pathology in The Akgüney Population: Stafne Cyst. Hitit University Journal of Social Sciences Institute, Symposium of AAHA, Special Issue, Year 11, Volume 2, October, 2018, ss. 977-990

Abstract: The Stafne Kist, also known as the Staphne cavity, Stafne defect, and lingual mandibular bone defect, was first described by Edward Stafne in 1942. Stafne Cyst is located on the lingual side of the mandible, anterior, posterior or ramus region. It is mostly seen as unilateral but rarely bilateral. The stafne cyst is round or oval shaped and varies in width $1-3 \mathrm{~cm}$. The frequency of Stafne cysts in living populations is between 0,1-0,48\%. The Stafne Kist, which is rarely encountered in archaeological societies, was determined to be $2.43 \%$ in Akgüney population dated to Late Roman-Byzantine period. In researches, Stafne cyst, which is more frequently observed in middle adult male subjects, was found in a young adult female individual in the Akgüney population. The aim of the study is to determine the frequency of stafne cyst in Akgüney society dated to Late Roman-Byzantine period.

Keywords: Stafne Cyst, Akgüney, Byzantium

\section{GÍRIŞ̧}

İnsanın kemik ve diş yapısının incelenmesiyle bireye dair birçok fizyolojik özelliklerin ortaya çıkartılması mümkündür. İnsanın ölümünden öncesine ait farklı bilgiler kemik ve dişler yardımıyla tespit edilebilir.

Stafne kist olarak isimlendirilen olgu ilk defa 1942 yılında bilim adamı Edward Stafne tarafından bilim literatürüne kazandırılmıştır (Resim 1). Stafne (1942), en geç 33 yaş en yaşlısı 72 yaşına olan 28'i erkek, 6's1 ise kadın olmak üzere toplam 34 birey üzerinde inceleme yapmıştır. Stafne (1942), çalışmasında ağı içi röntgenlerle tesadüfen karşılaştığı çene üzerindeki boşlukların 1-3 cm arasında değişiklik gösterdiğini ve mandibular kanalın hemen altında, mandibular açının ilerisinde 3.molara doğru yerleştiğini belirtmektedir. Stafne kistin şekli yuvarlak ya da ovaldir ve şekli oval olduğunda mandibula gövdesinin eksenine paralel olarak uzanır ve en büyük ölçüye sahiptir (Stafne,1942:1969). 


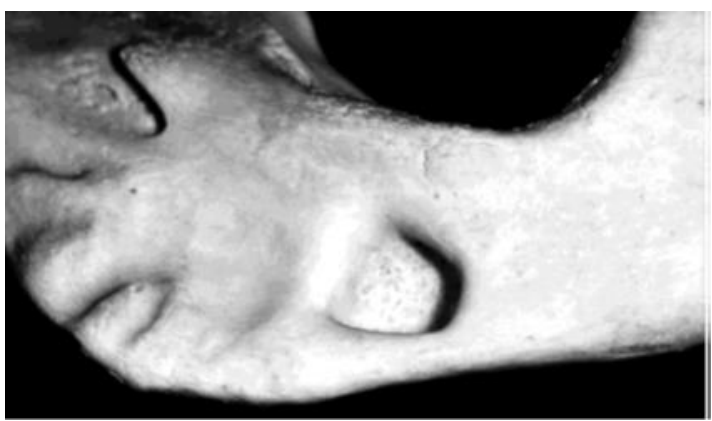

Resim 1. Stafne Kist (Shields,2000)

Stafne kist genellikle mandibulanın lingual tarafında bulunur ve çoğunlukla unlateraldir. Stafne (1942) yapmış olduğu çalışmada biri hariç diğerlerinin unlateral olduğunu tespit etmiştir. Queiroz ve arkadaşları (2004:613) çalışmalarında 32 yaşındaki bir kadın bireyin mandibulasında bilateral stafne kist tespit etmişlerdir. Şekerci ve Şişman (2014:115) aynı şekilde araştırmalarında bilateral stafne kist tespit ettiklerini bildirmektedir. Stafne kist, farklı isimlerle anılmakla birlikte en çok kullanılan isimleri Stafne kist ve Stafne kusurudur. Bu kemik kavitesini tanımlamak için kullanılan diğer isimler ise statik kemik kisti, boşluk (cavity), çukurluk (concavity), latent kemik kisti, mandibular embriyonik kusur, lingual kortikal mandibular defekt, mandibulanın idiyopatik kemik konkavitesi, lingual mandibular tükürük bezi depresyonu, mandibulanın gelişimsel submandibular bez kusurudur (Grellner vd,1990:288; Ariji vd,1993: 376; Philipsen vd,2002; Quesada-Gómez vd;2006:277 Şişman vd, 2010; Bereket vd,2012:250; Kürklü vd,2012:10; Mann ve Hunt, 2012:47-49; Şişman vd,2012; Türkoğlu vd,2012:44; Lee vd,2015:841; Mann ve Tuamsuk, 2016:906).

Stafne kistin etiyolojisi ile ilgili çeşitli görüşler bulunmaktadır. Stafne kisti ilk tanımlayan Stafne (1942), Stafne kistin konjenital olduğunu savunmaktadır. Stafne’ye göre mandibulanın lingual yüzeyinde meydana gelen boşluğun daha önce Meckel kıkırdağının işgal ettiği bölgelerde kaynaşmanın başarısız olmasından kaynaklanmaktadır. Ancak bilim insanları 11 yaşından daha küçük bireylerde bu anomaliyle karşılaşılmadığ için bu görüşe şüphe ile yaklaşmaktadır. Bilim insanları arasında en yaygın görüş glandüler hipotezidir (Quesada-Gómez vd,2006:278; Kürklü vd,2012:10; Lee,2015:842; Anbiaee vd,2016:40; Mann ve Tuamsuk,2016:908). Bu hipoteze göre, stafne kist mandibulaya ait lingual kortikalde glandüler doku tarafından uygulanan baskıdan kaynaklanmaktadır. Bununla birlikte Minowa ve arkadaşları (2006), 
mandibulanın lingual tarafinda dar bir taban ile statik bir kemik boşluğunu tanımlamış ve bu dar tabanın bulunmasının, basınç ve anormal submandibular bez dokusundan kaynaklanan kaviteler teorisini desteklemediğini iddia etmiştir. Ek olarak, 10 yaşından küçük hastalarda statik kist vakalarını tanımlayan bir rapor bulunmaması, Stafne'nin erken kemik malformasyonları teorisine çeliştiğini belirtmektedir. (Minova vd,2016:706). Mann ve Tuamsuk (2016), diğer araştırmacıların görüşleri doğrultusunda stafne kistin oluşumuyla ile ilgili görüşleri 4 başlık altında toplamıştır. Buna göre;1- Embriyonik gelişim sırasında anormal tükürük bezi dokusuna neden olur. 2-Fasiyal arter tarafından basınç erozyonu. 3Bitişik yumuşak dokuların genişlemesi sonucu, ağırlıklı olarak submandibular tükürük bezi. 4-Mandibula kemikleşmesinin lokalize başarısızlığı (Mann ve Tuamsuk, 2016:908).

Stafne (1942), Stafne kistin görülme yaşını genellikle 50 ila 60 yaşlar olduğunu belirtmektedir. Çeşitli araştırmacılar tarafından yapılan çalışmalar Stafne kistin görülme yaşının 29-75 arasında olduğunu göstermiştir (Ogunsalu vd;2006; Quesada-Gómez vd;2006; Wasterlain ve Silva,2012:427). Bununla birlikte en erken örnek ilk defa Hansson (1980:376) tarafından yaşayan 11 yaşında bir erkek çocuğunda tespit edilirken, Friedrich ve arkadaşları (2012) klinik çalışmalar sırasında 11 yaşındaki bir kız çocuğunda stafne kist tespit etmiştir (Friedrich vd,2012:1103). Mann (1990) ise 10-12 yaşlarındaki bir çocuğa ait iskelette stafne kist tespit ettiğini bildirmiştir (Mann ve Tuamsuk,2016).

Stafne kist araştırmacılar tarafından mandibulada bulunduğu lokasyona göre, anahatlarına ve bukkal kortikal plaka ile olan ilişkilerine göre ve kortikal defekt kenarlarına göre sınıflandırılmıştır. Stafne kist, mandibulada bulunduğu bölgeye göre 4'e ayrılır. Buna göre; Posterior Lingual Tip; 1.molar ve mandibula açısı arasında, inferior kanalın altında yer alır. Anterior Lingual Tip: Mylohyoid kasın yapışma izinin üstünde, incisive ile premolar arasında yer alır ve posterior tipe göre 7 kat daha az görülür. Ramus Tip: Ramusun bukkal veya lingualinde olmak üzere 2 farklı tipi bulunmaktadır (Resim 2) (Quesada-Gómez vd, 2006:278; Aguiar vd,2011:1; Bereket vd,2012:250; Türkoğlu vd,2012:43; Bignone vd,2017). En sık karşılaşılanı posterior lingual tipi iken anterior lingual tip daha az görülür, en nadir görülen tip ise ramus tipidir (Bereket vd,2012:250). 

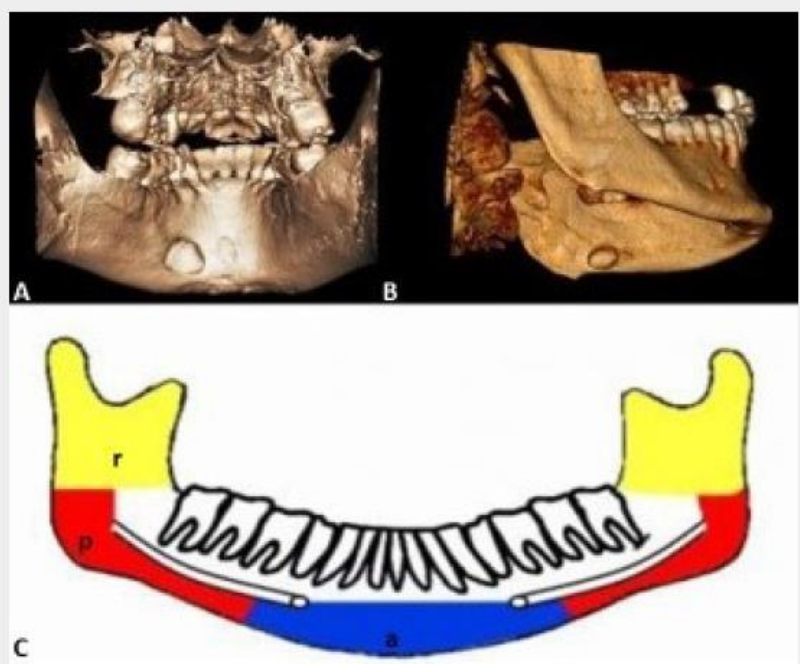

Resim 2. Stafne Kistin lokasyonunda göre sinıflandırılması, A. Anterior Tip B.Posterior Tip C. RamusTip. Ogunsalu vd;2006;Bignone vd,2017.

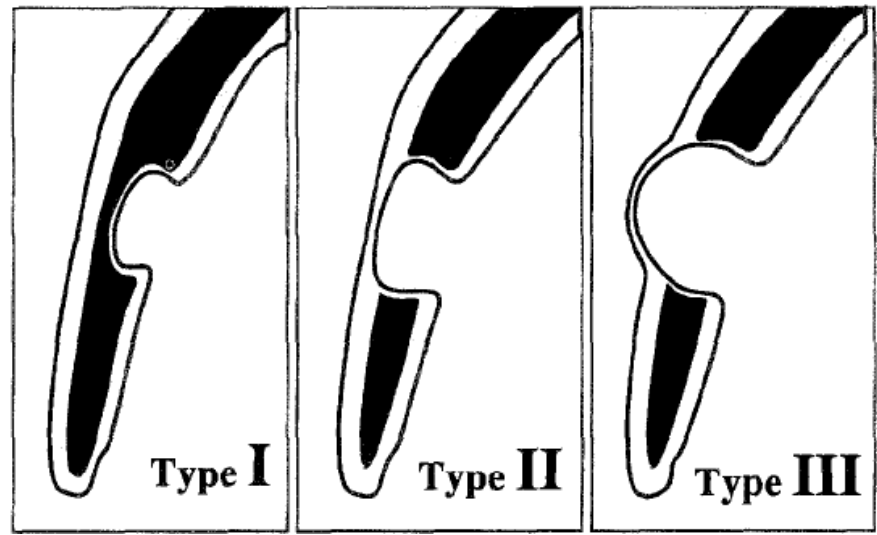

Resim 3. Anahatlarına ve bukkal kortikal plaka ile olan ilişkilerine göre Stafne Kistin siniflandırılmas1, (Ariji vd,1993). 
Anahatlarına ve bukkal kortikal plaka ile olan ilişkilerine göre sınıflandırılmasına bakıldığında ise Tip 1: Boşluk bukkal kortikale ulaşmaz. Tip 2: Boşluk tabanı bukkal kortikal plakaya ulaşır, ancak plak genişlemez ve bozukluk görülmez. Tip 3: Kortikal plağın bukkal genişlemesi ile karakterizedir (Resim 3) (Ariji,1993:376; Ogunsalu,2006:449).

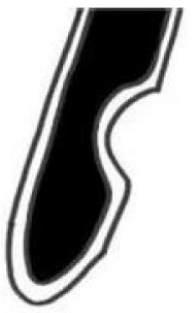

broad type

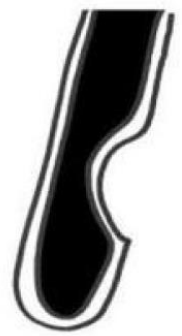

smooth margin

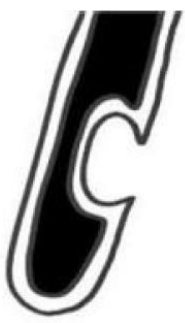

narrow type

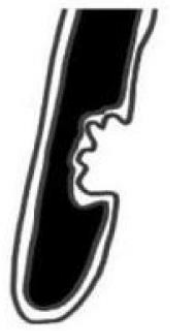

irregular margin

Resim 4. Stafne Kistin Kortikal Defekt Kenarlarına Göre Sinıflandırılmas1, Minowa vd,2003; Bignone vd,2017

Minowa ve arkadaşları (2003), Kortikal defekt kenarlarının yapısına göre Stafne kisti 4 gruba sınıflandırmıştır (Resim 4). Buna göre; a-Geniş tip, bDar tip, c-Düz tip, d-Düzensiz tip (Minowa vd,2003; Bignone vd,2017).

Stafne kist klinik bulgularda görülme sıklığ1 \%0,1-0,48 arasında değiştiği bildirilmiştir (Oikarinen ve Jilku,1974:71; Correll vd,1980:287; Philipsen vd,2002). Oikarinen ve Jilku (1974) 10000 ortopanografik görüntüde sadece 10 bireyde $(\% 0,1)$ stafne kist olgusuna rastladıklarını belirtirken, Correll ve arkadaşları (1980) ise 2693 oral panoramik radyografı gözden geçirmiş ve 13 bireyde $(\% 0,48)$ stafne kist olgusunu tespit etmiştir. Philipsen ve arkadaşları ise inceledikleri 42600 adet radyografik görüntüde $69(\% 0,16)$ adet stafne kist olgusu testpit etmiş ve posterior stafne kist oranını $\% 0,009$, anterior 
stafne kist oranını ise \%0,15 olarak bildirmiştir (Philipsen vd,2002). Quesada-Gómez ve arkadaşlarının (2006) yapmış olduğu çalışmada stafne kist oran1 \%6,06 olarak bulunmuştur (Quesada-Gómez vd,2006). Türkiye'de yapılan çalışmalara bakıldığında ise, Şahin ve arkadaşları tarafından 1471 hasta üzerinde yapılan inceleme sonucunda $8(\% 0,54)$ bireyde stafne kist olgusuna rastlamışlardır. Tespit edilen stafne kistlerden 4'ü sağ, 4'ü ise sol tarafta olduğu bildirilmiştir (Şahin vd,2005:40). Münevveroğlu ve Aydın'ın (2012) 7922 hasta üzerinde yapmış oldukları çalışma sonucunda ise Stafne kist oranı \%0,025 (n:2) olarak tespit edilmiştir (Münevveroğlu ve Aydın,2012:2). Şişman ve arkadaşlarının (2012) 34221 hasta üzerinde yapmış oldukları çalışma sonunca ise 29 (0,08\%) bireyde stafne kist tespit edilmiştir. Stafne kist tespit edilen bireylerin 4'ü kadın, 25’i ise erkek birey olduğu bildirilmiştir (Şişman vd,2012).

Stafne kistin arkeolojik iskelet serilerinde bulunma sıklığıla ilgili çalışmalara bakıldığında ise Finnegan ve Marcsik (1980), Macaristan'daki arkeolojik alanları incelemiş ve toplam 5519 mandibula örneğinin 59'unda (\% 1,07) Stafne kist olduğunu bulmuştur (Finnegan ve Marcsik,1980:19). Lukacs ve Rodriguez Martin (2002), Kanarya Adaları'ndaki (İspanya) Tenerife'nin tarih öncesi iskeletlerine görülen stafne kist sıklı̆̆ını \%3,32 olarak hesaplamıştır. Lukas ve Rodriguez Martin(2002) çalışmalarında Kanarya adalarında bulunan tarihöncesi döneme ait olan Guanche mandibula örneklerinde stafne kist sıklığını \% 3,32 (15/452) olarak bulmuştur. Çalışmada erkeklerin $(\% 0,67)(10 / 15)$ kadınlara göre $(\% 0,33)(5$ /15) daha yüksek olduğu belirtilmektedir (Lukas ve Rodriguez Martin,2002:112). Masnicova ve Benus (2003), Devin (Slovakya) Orta Çağa tarihlendirilen Devín-Hrad (DH) arkeolojik siteden ele geçirilen 84 bireyden 1'inde $(\% 1,19)$ stafne kist tespit ederken, Great Moravian 9. yüz ylla tarihlendirilen DevínZa kostolom (FR) arkeolojik sitesinden ele geçirilen 40 bireyin 2'sinde (\%5) Stafne kist tespit edilmiştir (Masnicova ve Benus,2003:268-269). Jordana ve arkadaşları (2007), Ortaçağa tarihlendirilen 40-50 yaşlarında bir erkek bireye ait iskeletin mandibulasında stafne kist tespit etmişlerdir (Jordana vd,2007:557). Araştırmacılar mandibula açısının yakınında ikinci ve üçüncü sağ moların altında posterior bölgede yer alan unlateral ve yan yana iki ayrı stafne kist olduğunu belirtmektedir (Jordana vd,2007:558).Vodanovic ve arkadaşlarının tarih öncesi döneme tarihlendirilen 5071 iskelet üzerinde yaptıkları çalışmada stafne kist oranı \% 0,05 (kadın\% 0,00 ve erkekler\% 0,13) olarak 
tespit edilmiştir (Vodanovic vd,2011). Araştırmacılar, Antik örneklerde Stafne'nin kusurunun görülme sıklığını \% 0,11, (1/875) (kadın\% 0,00 ve erkek \% 0,34) olarak tespit ederken, Geç Ortaçağ örneklerinde \% 0,06 (1/1561) (kadın\% 0,00 ve erkek \% 0,18) olarak bulmuştur (Vodanovic $\mathrm{vd}, 2011)$.

Anadolu'da ise iskeletler üzerine stafne kist ile ilgili yazılmış tek bir çalışma mevcuttur. Anagnostis'in (2014) yapmış olduğu çalışmada M.Ö.7.yya tarihlenen Klazomenai (Akpınar) nekropolünden ele geçirilen 55-60 yaş arası erkek bireyde stafne kist olgusunun tespit edildiği belirtilmektedir (Anagnostis,2014:362-366). Stafne kistin mandibulanın sol posterior lingual tarafında, unlateral, düz ve oval şeklinde olduğu bildirilmiştir (Anagnostis,2014:362). Ölçüleri ise genişlik 10,93×13,37 mm iken derinliği 0,82 ile 1,64mm arasında değişmektedir (Anagnostis, 2014:362).

\section{II.MATERYAL- METOT}

Karadeniz kıyısında yer alan Akgüney Nekropolü; Sinop ili Gerze ilçesine bağlı Akgüney Köyünde 2015 yılı içerinde başlayıp tamamlanan Geç RomaBizans dönemine tarihlendirilmiş bir arkeolojik alandır. Sinop Müzesinin yapmış olduğu kurtarma kazısı neticesinde nekropol içerisinde çoğunluğunu Bizans Dönemine tarihlendirilen 96 mezar içerisinden toplam 170 bireye ait iskelet elde edilmiştir. Araştırmacı Çırak (2017) yaptığı paleodemografik çalışmada Akgüney Toplumunun \%26,5 oranında erkek bireylerden oluştuğunu tespit etmiş, kadınlarda bu oranı \%25,2 olarak bulmuştur. Geriye kalan yaklaşık \%40'lık bir oranda cinsiyeti belirlenemeyen bireylerden ve bebek ve çocuklardan oluşmuştur. Cinsiyeti belirlenemeyen bireyler tüm toplum içerisinde yaklaş1k \%21,8 iken \%20'lik bir oranda Akgüney Geç Roma-Bizansa ait bebek ve çocuk bireylerin varlığ tespit edilmiştir (Çırak, 2017:254).

Akgüney toplumuna ait 22'si kadın, 14'ü erkek ve 5'i izole olmak üzere 41 mandibula makroskobik olarak incelenmiştir. Yapılan incelemeler sonucunda 32 yaşındaki bir kadın bireyde stafne kist tespit edilirken (Resim 5), erkek bireylerde ve izole mandibulalarda stafne kist olgusuna rastlanılmamıştır. Geç Roma-Bizans Dönemine tarihlendirilen Akgüney toplumunda stafne kist görülme sıklı̆̆1 \%2,43 olarak tespit edilmiştir. Bu oran kadın bireylerde \%4,54 olarak tespit edilmiştir. Akgüney toplumunda tespit edilen stafne kist bulunmuş olduğu lokasyona göre değerlendirildiğinde posterior tip olduğu görülmektedir. Anahatlarına ve 
bukkal kortikal plaka ile olan ilişkilerine göre değerlendirildiğinde ise Tip 1 olarak sınıflandırılmıştır (Resim 6). Kortikal defekt kenarlarının yapısına göre sınıflandırılması ise düz tipe dahil edilmiştir. Akgüney toplumunda tespit edilen stafne kistin şeklinin ise oval olduğu görülmektedir. Stafne kistin ölçüleri ise;6,37 mm x3,79'dur.

Stafne kist tespit edilen bireyin diş aşınması ileri derecedir. Ayrıca stafne kistin tespit edildiği sol mandibulada birinci ve ikinci molarda, sağ tarafta ise 1.moların ante-mortem olarak kaybedildiği gözlenmiştir. Bireyde diş taş1 oluşumu neredeyse yoktur. Diş çürüğü açısından incelendiğinde ise sağ ikinci incisivin distali ile sağ caninin mesiali arasında ve sol 3.molarda çürük oluşumu tespit edilmiştir. Bireyin dişlerinde hypoplasyaya rastlanılmamıştır (Resim 7).

\section{DEĞERLENDİRME - SONUÇ}

Stafne Kist (Stafne kusuru veya pseudo kist) çeşitli isimlerle anılan ve nadir görülen bir patolojidir. Güncel örnekler üzerinde yapılan araştırmalarda radyografik incelemeler kullanılmakta olup arkeolojik buluntular elde edilen iskeletlerin makroskopik incelemeleriyle ortaya konabilmektedir. Stafne kist her ne kadar patolojik bir oluşum olarak değerlendirilmese de varyasyon mu patoloji mi olduğu konusu tartışmalıdır. Zira varyasyon olarak değerlendirme yapılmasında etken sebep herhangi bir sağlık soruna bağlı bir semptom olarak belirlenmemesidir. Ancak literatürde geniş bir kabul ile patoloji olarak değerlendirilir. Yapılan güncel araştırmalarda da yoğun olarak patolojik bir oluşum olarak varlıkları röntgen cihazları ile tespit edilmeye çalış1lır. Özellikle Arkeolojik kazılar neticesinde bulunan iskeletlerde araştırması yapılan stafne kist, postmortem veya antemortem kırıklar ile karıştırılabilmektedir. Hem bu yüzden hem de nadir görülen patolojik bir oluşum olduğu için stafne kistinin varlığının tespitinde zorluklar yaşanmaktadır. Gerek eski Anadolu toplumları, gerek ise diğer coğrafi alanlarda yapılan arkeolojik ve antropolojik değerlendirmelerde farklı sonuçlar elde edilmiştir. Stafne kistin bebek veya çocuk iskeletlerinde hiç rastlanmaması konjenital olduğuyla ilgili hipotezlerle çelişmektedir. Yapılan çalışmalar stafne kistin daha çok erkek bireylerde karşılaşıldığını göstermektedir. Stafne kistin görülme yaşı çoğunlukla 29-75 yaşları arasında değişmektedir. Ancak nadir de olsa 11-12 yaşındaki çocuklarda da stafne kist olgusunun bulunduğu araştırmacılar tarafından bildirilmiştir. 
Akgüney toplumunda tespit edilen stafne kist örneği ise genç erişkin (32 yaş) kadın bireye aittir.

Stafne kist ile ilgili yaşayan toplumlar üzerinde yapılan araştırmalar çok nadir rastlanılan bir patolojik olgu olduğunu göstermektedir. Günümüz toplumlarında stafne kist görülme sıklı̆̆1 \%0,1-0,48'dir. Ancak QuesadaGómez ve arkadaşlarının (2006) kadavralar üzerinde yaptıkları çalışma sonucu stafne kist oranını \%6,06 oranında olduğu belirtilmektedir. Arkeolojik toplumlarda ise görülme oranı \%0,06 ile \%5 arasında değişmektedir. \%5 ile en yüksek orana sahip arkeolojik site Great Moravian 9. yüz yıla tarihlendirilen DevínZa kostolom'dur. Yapılan çalışmada 40 bireyden 2'sinde stafne kist tespit edildiği bildirilmiştir. Geç Roma-Bizans Dönemi Akgüney toplumunda ise stafne kist görülme sılklı̆̆ ise \%2,43'tür (n:1/41).

Stafne kistin şekli yuvarlak ya da oval olabilmektedir. Akgüney Toplumunda 32 yaşındaki kadın bireyde tespit edilen stafne kistin şekli ovaldir ve sol mandibulanın posteriorunda unlateral olarak yer almaktadır. Stafne kistin bulunduğu lokasyona göre posterior tip, Anahatlarına ve bukkal kortikal plaka ile olan ilişkilerine göre değerlendirildiğinde ise Tip 1, kortikal defekt kenarlarının yapısına göre sınıflandırılması ise düz tip olduğu tespit edilmiştir.

Stafne kistle ilgili yapılan çalışmalar çoğunlukla yaşayan bireyler üzerinde yapılmıştır. Arkeolojik kazılardan ele geçirilen iskeletler üzerine yapılan çalışmalar ise oldukça azdır. Özellikle geçmiş dönemlerde yaşamış olan Eski Anadolu Toplumları ile ilgili yapılmış çok az çalışmanın olduğu görülmüştür. $\mathrm{Bu}$ durumun gerek çok az rastlanılan patolojik bir olgu olması gerekse kazı çalışmaları sırasında ya da iskelet materyallerin taşınması ve temizlenmesi sırasında oluşan postmortem kırıklar nedeniyle tespit edilme olasılığının azalmasından kaynaklandığı düşünülmektedir. Bu çalışma stafne kist olgusunun Eski Anadolu toplumlarında görülme sıklı̆̆ının belirlenmesi açısından yapılan sayılı çalışmalardan biri olması bakımından oldukça önemlidir. 


\section{Teşekkür}

Çalışmanın yapıldığı iskelet materyalleri sağlayan ve desteklerini esirgemeyen Sinop Müzesi Müdürü Sayın Hüseyin Vural'a ve Sinop Müzesi çalışanlarına, Hitit Üniversitesi Bölüm Başkanı Sayın Dr. Öğr. Ü. Mustafa Tolga Çırak'a, Hitit Üniversitesi Antropoloji Bölümü lisans öğrencilerine teşekkürü bir borç bilirim.

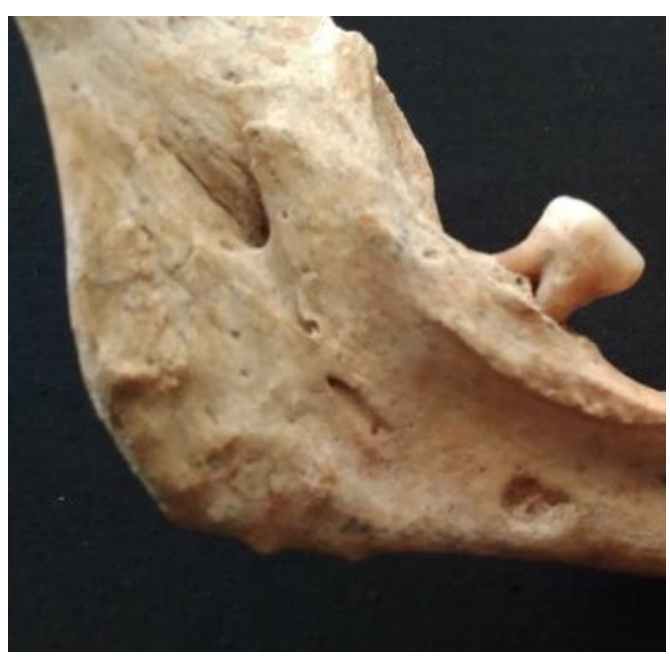

Resim 5. Akgüney Toplumu Stafne Kist

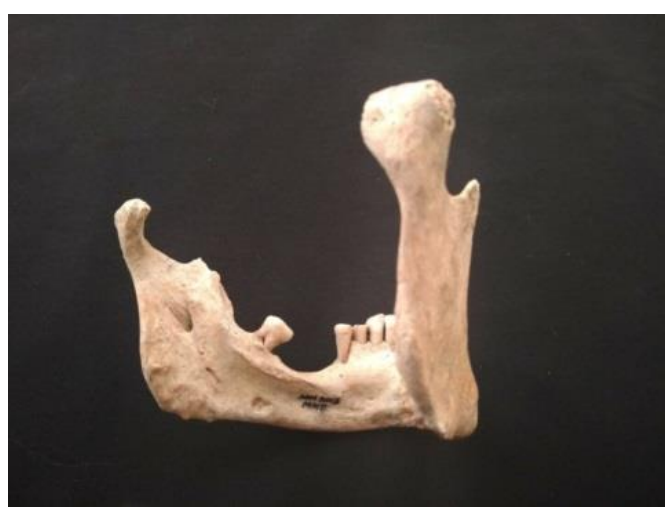

Resim 6. Akgüney Toplumu Stafne Kist Posterior tip 


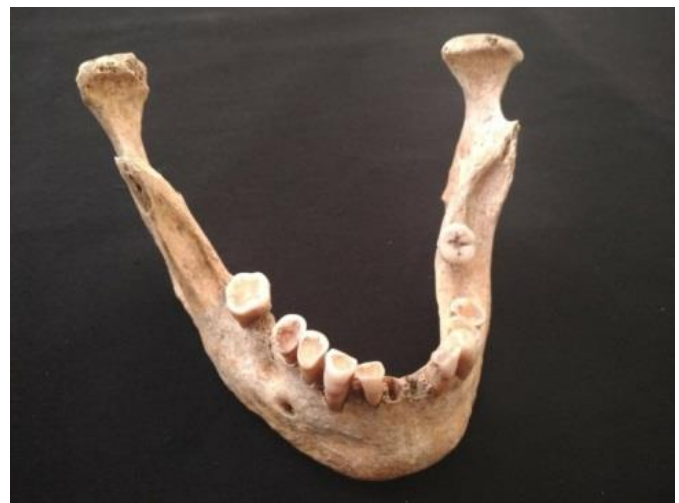

Resim 6. Diş Patolojileri

\section{KAYNAKÇA}

AGUIAR vd.(2011). Multiple Stafne Bone Defects: A Rare Entity, ISRN Dentistry;1-3

ANAGNOSTIS, A. P. (2014). An Ancient Greek Veteran-Warrior With Stafne's Cavity, Mediterranean Archaeology and Archaeometry, Vol. 14, No 2, pp. 361-366 MAA Printed in Greece.

ANBIAEE vd. (2016). Stafne bone defect in the ramus of the mandible: A Case Report., Journal of Dentomaxillofacial Radiology, Pathology and Surgery, Vol 5, No 1, Spring 2016 (37-41)

ARIJI vd. (1993). Stafne's bone cavity Classification based on outline and content determined by computed tomography, Oral Surg, Oral Med, Oral Pathol 1993; 76:375-380

BEREKET vd.(2012). Yağ dokusu İçeren nadir bir stafne kemik kavitesi olgusu, Cumhuriyet Dent J,15(3): 249-254 doi:10.7126/cdj.2012.989

BIGNONE, vd.(2017). Stafne Bone Cyst in the Anterior Mandible: An Unusual Location,e-Poster: 261,Congress: ESHNR 2017

CORREL vd. (1980). Lingual cortical mandibular defects: a radiographic incidence study, Oral Surg, Oral Med Oral Pathol;50(3):287-91.

CIRAK, M. T. (2017). Akgüney Gec Roma- Bizans Dönemi Topluımu Üzerine Paleodemografik Çalışma, Hitit Üniversitesi Sosyal Bilimler Enstitüsü Dergisi, Yı1 10, Say1 1, Haziran 2017, ss. 249-264

FINNEGAN, M. MARCSIK, A. (1980). Anomaly or pathology: the Stafne defect as seen in archaeological material and modern clinical practice, Journal of Human Evolution 9: 19-31

FRIEDRICH vd. (2012). Anterior Lingual Mandibular Bone Depression in an 11-Yearold Child, in vivo 26: 1103-1108.

GRELLNER vd.(1990). Lingual mandibular bone defect: Report of three cases, J Oral Maxillofac Surg, 1990;48:288-96.

HANSSON, L.G. (1980). Development of a lingual mandibular bone cavity in an 11year-old boy, Oral Surg, Oral Med Oral Pathol;49(4):376-378. 
JORDANA vd. (2007). Report on a Stafne Defect in a Man From Medieval Age, Journal of Oral and Maxillofacial Surgery,April 2007,DOI: 10.1016/j.joms.2005.07.023 . Source: PubMed

KÜRKLÜ vd.(2012). Stafne Kemik Kavitesi: İki Olgu Nedeniyle, Atatürk Üniv. Diş Hek. Fak. Derg. J, Dent Fac Atatürk Uni, Supplement: 5, Sayfa : 10-15

LEE vd. (2015), An Unusual Presentation of Stafne Bone Cyst, J. Maxillofac, Oral Surg, (July-Sept 2015) 14(3):841-844 DOI 10.1007/s12663-014-0737-2.

LUKACS, J.. R. RODRIGUEZ MARTIN, C. (2002). Lingual Cortical Mandibular Defects (Stafne's Defect): An Anthropological Approach Based on Prehistoric Skeletons from the Canary Islands, International Journal of Osteoarchaeology Int. J. Osteoarchaeol,12:112-126, Published online in Wiley InterScience (www.interscience.wiley.com). DOI: 10.1002/oa.592

MANN, R.W. (1990). Incipient lingual cortical mandibular defect in a 10- to 12 -yearold American Indian child, American Journal of Roentgenology 154: 658-659.

MANN, R. W. HUNT, D.R.,(2012). Photographic regional atlas of bone disease : a guide to pathologic and normal variationin the human skeleton, Published, Charles C. Thomas Publisher, Ltd. ISBN 978-0-398-08827-9 (ebook).3rd ed, 47-49.

MANN, R.. W. TUAMSUK, P. (2016). Stafne's Defects in a Sample of Adult Thai, Mandibles in the Khon Kaen University Osteology Collection, Thailand, International Journal of Osteoarchaeology, Int. J. Osteoarchaeol. 26: 906-911, Published online 24 February 2016 in Wiley Online Library(wileyonlinelibrary.com) DOI: 10.1002/oa.2508

MASNICOVA, S. BENUS, R.(2003). Developmental Anomalies in Skeletal Remains from the Great Moraviaand Middle Ages Cemeteries at Devi'n (Slovakia), International Journal of Osteoarchaeology Int. J., Osteoarchaeol. 13: 266-274, Published online in Wiley InterScience (www.interscience.wiley.com). DOI: $10.1002 /$ oa. 684

MINOWA vd. (2003).Evaluation of static bone cavities with CT and MRI, Dentomaxillofac Radiol, 2003; 32:2-7

MINOWA vd. (2006).Static Bone Cavity of the Mandible: Computed Tomography Findings with Histopathologic Correlation, Acta Radiologica, 47:7, 705-709

MÜNEVVEROĞLU, A.P. AYDIN, K. C. (2012). Stafne Bone Defect: Report of Two Cases, Hindawi Publishing Corporation Case Reports in Dentistry, Volume 2012, Article ID 654839, 5 pages.

OGUNSALU vd. (2006). Radiological assessment of type II Stafne idiopathic bone cyst in a patient undergoing implant therapy: a case report, West Indian Medical $J$, 2006;55:447-450)

OIKARINEN, V J. JILKU, M. (1974). An orthopantomographic study of developmental mandibular bone defects (Stafne's idiopathic bone cavities), Int J Oral Surg 3:71-76

PHILIPSEN vd. (2002).Lingual and mandibular bone depressions: a review based on 583 cases from a world-wide iterature survey, including 69 new cases from Japan, Dentomaxillofac Radiol;31(2):281-90.

QUESADA-GÓMEZ vd. (2006). Stafne bone cavity: a retrospective study of 11 cases, Med Oral Patol Oral Cir Bucal;1 1(3):E277 280. 
QUEIROZ vd. (2004). Anterior bilateral presentation of Stafne defect: an unusual case report, J Oral Maxillofac Surg, 62:613-615.

SHIELDS, E. D.(2000). Technical Note: Stafne Static Mandibular Bone Defect-Further Expression on The Buccal Aspect of The Ramus, American Journal of Physical Anthropology 111:425-427 (2000).

STAFNE, E. C. (1942). Bone cavities situated near the angle of the mandible, J Am Dent Assoc;29:1969-72.

ŞAHIN vd. (2005). Stafne Kemik kavitesi, Türkiye Klinikleri, J.Dental Sci. 11: 39-42.

ŞEKERCİ vd. (2014). Bilateral anterior Stafne bone defect mimicking radicular cyst: Report of a rare case with a review of the literatüre, Oral Radiol, 2014;30:11522.

ŞİSMAN vd. (2010). Anterior Stafne bone defect mimicking a residual cyst: A case report, Dentomaxillofacial Radiology,39:124-126, 2010.

ŞISSMAN vd. (2012). Radiographic evaluation on prevalence of Stafne bone defect: a study from two centres in Turkey, Dentomaxillofacial Radiology, 41, 152-158 2012 The British Institute of Radiology

TÜRKOĞLU vd. (2012). Stafne kemik kavitesi: 3 olgu sunumu, Cumhuriyet Dent $J$, 2012;15(1):43-47.

VODANOVIC vd.(2011). A Stafne's Defects in Two Mandibles from Archaeological Sites in Croatia, International Journal of Osteoarchaeology Int. J.,Osteoarchaeol. 21: 119-126.

WASTERLAIN, S. N. SílVA, A. M.. (2012). Study of Stafne's Defects in Late Neolithic, Late Roman, Medieval and Modern Skeletal Samples from Portugal, International Journal of Osteoarchaeology (wileyonlinelibrary.com) DOI: 10.1002/oa. 1216 * 22: 423-434 (2012). 